\title{
ARM7 BASED Automatic Soot Blower CONTROL SYSTEM
}

\author{
Chayalakshmi C. L. ${ }^{1}$, D. S. Jangamshetti ${ }^{1}$ and Savita Sonoli ${ }^{2}$ \\ ${ }^{1}$ Basaveshwar Engineering College Bagalkot, Karnataka. \\ ${ }^{2}$ RYM Engineering College, Bellary, Karnataka.
}

\begin{abstract}
Boiler is a power house of any process industry. Soot and scale formation in boilers is still a great concern for increasing the efficiency of the boiler. At present, soot blowers are operated manually once in a shift. This paper presents one of the embedded based industrial automation techniques for efficient operation of soot blowers. An automation technique is designed and implemented in real time using ARM7 platform. Stack temperature is used as the criteria for controlling the soot blower. Embedded C language is used for implementing the automatic control algorithm. The performance of the designed system is tested in the laboratory.
\end{abstract}

\section{KEYWORDS}

ARM7, Boiler efficiency, Stack temperature, Soot blower

\section{INTRODUCTION}

The capital, land, and labor are the significant factors for the process industry. But energy cost also plays a very important role. Always there is a need for better quality, greater efficiency and automated machines in any industry [1], for maximizing the profit. As steam is colorless and odorless gas with the ability to carry and transfer large amount of thermal energy, it is used as source of energy in many industrial processes like sterilization, drying, cooking, cleaning etc. Boiler, a closed vessel, is one of the major components in most of the process industries for production of steam which is the main source of energy. A boiler converts water into steam under pressure due to combustion through the chemical reaction between fuel and the oxygen. Water is a cheap medium and available in abundance. But before feeding water to the boiler, it has to be treated chemically. The volume of steam is very high when compared with volume of water in the boiler. Due to this factor, the boiler must be treated with utmost care.

An efficient boiler converts all chemical energy released from the fuel in to heat energy and also it transfers the heat energy to the incoming water completely. It is not possible to achieve $100 \%$ efficiency, because of boiler losses. The boiler efficiency reduces with time, heat transfer fouling, poor combustion and poor operation and maintenance and hence, there is a need for real time monitoring of boiler efficiency regularly [2]. Input-Output or direct method and heat loss or indirect method, are the two ways of evaluating the boiler efficiency. In direct method, the ratio of output steam energy to input fuel energy is considered for evaluation of boiler efficiency [3-5]. Though it is an easy method it does not provide any explanation or reason about the reduction in boiler efficiency. In indirect or the heat loss method, boiler efficiency is evaluated by subtracting overall boiler losses from maximum theoretical boiler efficiency. It provides the appropriate reason for the boiler efficiency. The following are the boiler losses that are evaluated to find the boiler efficiency in indirect method: 
1. Loss due to the heat carried by the dry flue gas through the chimney.

2. Loss due to the heat carried away by the moisture and hydrogen via the chimney.

3. Loss due to heat radiated from the outer surfaces of the boiler.

4. Loss due to boiler blow down. When steam is generated, the concentration of suspended solids present in feed water causes reduction in efficiency of a boiler [6].

5. Loss due to unburnt carbon and gas, due to incomplete combustion.

Among all these losses, the loss due to dry flue gas is maximum. Amount of excess air, firing rate, cleanliness of heat exchange surfaces, operational temperature, operational pressure and the design of appliance are the factors affecting the final stack temperature which in turn contribute to major loss due to dry flue gas. According to the basics of boiler, the maximum permissible stack temperature is $40{ }^{\circ} \mathrm{C}$ more than the saturation temperature of steam. One of the main reasons for increase in stack temperature is due to the deposition of soot on heat transfer surfaces inside the boiler. Incomplete combustion results in soot accumulation on the combustion side of tubes and poor water treatment results in scale formation on the inner wall (water side) of the tubes. Scale and soot formation in the boiler reduces the heat transfer rate from the fuel to the water. There is a possibility of fire in stack due to incomplete combustion and may cause boiler explosion. Ash deposition on the heat transfer surfaces is still a problem in coal fired boilers in an industry.

Almost all power plant boilers use coal as a fuel for generation of steam. Soot formation in combustion is due to the presence of mineral material of various forms. This deposits on the heat transfer surfaces of boiler, reduces the rate of heat transfer between burner and the water, which in turn reduces the steam output resulting loss in thermal efficiency and increased corrosion problem [7]. Sections of steam generation are kept clean by soot blowers. Power plant performs soot blowing action on regular basis without measuring any plant parameters. This results in cleaning some areas excessively and lack in other areas. Amount of steam is wasted in excessive cleaning areas and results in tube surface erosion [8].

\subsection{Drawback of conventional system}

At present, the following are the traditional and manually controlled methods available for removal of soot deposition:

1. High pressure and high temperature steam is used to blow away the ash fouling.

2. A number of soot blowers are continuously initiated according to the predefined sequences and a fixed schedule. Soot blowers available in market today, which are manually operated are:

i. Long retractable soot blowers

ii. Wall/ short retractable soot blowers

iii. Rotary soot blowers

iv. Rake soot blowers.

A manual soot blower cleans the surface of the boiler by blowing air or steam at high pressure, so as to remove the soot. But the soot blower is turned on for a predetermined time, once in a shift, without any scientific justification [9]. Sometimes, even when there is no deposition or very less deposition, the operator turns on soot blower for the same duration, which leads to wastage of energy and increases the maintenance cost. Traditional methods for reducing the soot formation are not much efficient, as manual intervention is involved. Hence there is a requirement of intelligent and automated system for controlling the soot formation, so as to reduce the dry flue gas loss and increase the efficiency of a boiler. 
In one more existing method uses relay contactors, which are not reliable, difficult wiring diagram, and more maintenance cost. This work focuses on use of Programmable Logic Controller (PLC) to control the steam blowing system [10]. The initial investment and maintenance cost of the system increases as it is based on PLC.

This paper describes an embedded based soot blower and stack temperature control system. In this system the soot blower is controlled based on the rise in stack temperature.

\section{BASIC BOILER SYSTEM}

The boiler is an essential component in most of the process industries, as it provides the necessary steam at various pressures. Feed water system, steam system and fuel system are the three sub systems of the boiler.

The feed water system regulates the feed water to meet the steam demand. Different types of valves are used for this purpose. There are two sources of feed water: condensed steam returned from the process and chemically treated water, from outside the boiler. The generation of steam is due to evaporation of feed water. To get better efficiency, the feed water is preheated by the economizer which uses the waste heat in the flue gas.

The steam system collects and controls the steam produced in the boiler. Proper piping system is used to direct the steam to the point of use. The pressure of steam is regulated using valves and measured with steam pressure gauges.

The fuel system includes various components like valves, gauges, burners to provide the necessary fuel, so as to generate heat. The components of fuel system mainly depend on the type of fuel used for combustion. A typical boiler schematic is shown in Figure 1. The following are the some of the general rules related to an industrial boiler [11]:

- $1 \%$ boiler efficiency increases, if $5 \%$ excess air is reduced.

- Boiler efficiency increases by $1 \%$ if the flue gas temperature is reduced by $22{ }^{\circ} \mathrm{C}$.

- Boiler fuel consumption reduces by $1 \%$ when the feed water temperature rises by $6{ }^{\circ} \mathrm{C}$.

- $1 \%$ fuel would be saved when the combustion air temperature increases by $20^{\circ} \mathrm{C}$.

- $2.5 \%$ fuel consumption increases due to $3 \mathrm{~mm}$ thick soot deposition on a heat surface.

- Fuel consumption increases by 5 to $8 \%$ when a $1 \mathrm{~mm}$ thick scale deposits on the water side.

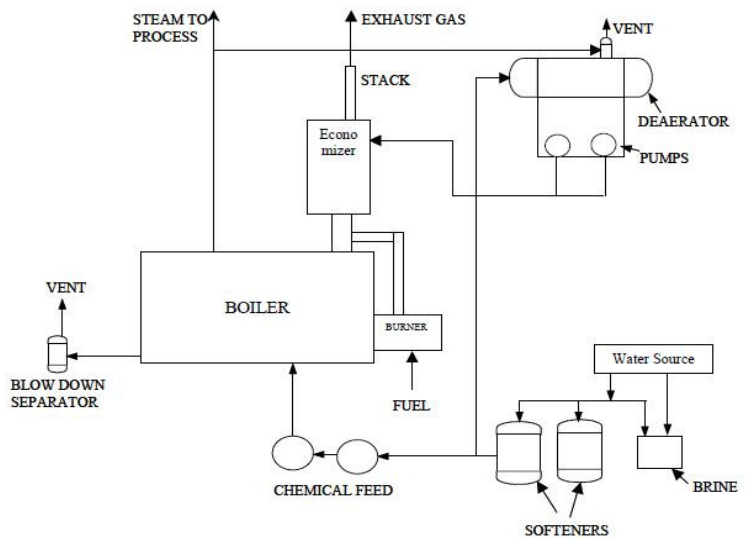

Figure 1. A typical boiler schematic [9] 


\section{The Soot Blower Control System}

The block diagram of stack temperature measurement and soot blower control system is illustrated in Figure 2. The stack temperature is measured and controlled at the desired value. As the soot formation increases in the boiler, stack temperature increases due to lesser heat transfer. This reduces the efficiency of boiler, due to incomplete transfer of heat from fuel to water. Decrease in efficiency indicates increase in fuel consumption. A $3 \mathrm{~mm}$ thick soot deposit on the heat transfer surface can cause a 2.5 percent increase in fuel consumption and also, $22{ }^{\circ} \mathrm{C}$ reduction in flue gas temperature increases the boiler efficiency by 1 percent [12].

Temperature of the stack is measured using a $\mathrm{K}$ type thermocouple. The voltage output of this thermocouple is enhanced with signal conditioning circuit. The in-built 10 bit ADC of ARM controller converts the analog voltage to digital number. The display on the LCD is calibrated in terms of temperature. The soot blower motor is controlled by the algorithm implemented in the same processor. The temperature sensor with signal conditioning circuit and the control circuit for soot blower are shown in Figure 3 and Figure 4 respectively.

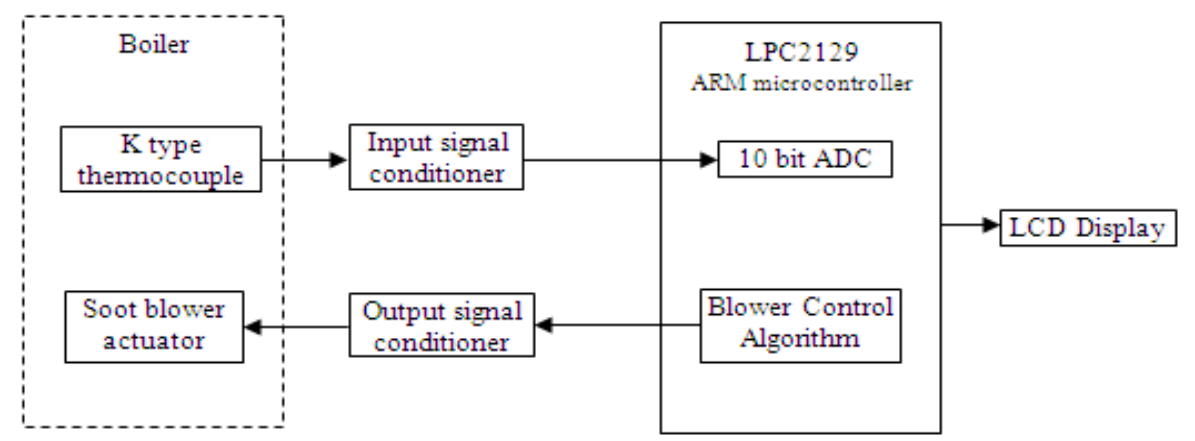

Figure,2. Block diagram of soot blower control system

\subsection{Temperature Sensor}

The stack temperature is measured using a K-type thermocouple which is made up of Chromel and Alumel alloys. The output signal is fairly linear in the required range and the resolution is 41 $\mu \mathrm{V} /{ }^{\circ} \mathrm{C}$.

\subsection{Instrumentation Amplifier}

Instrumentation amplifier AD620 is used for conditioning the signal from the temperature sensor. AD620 has an input offset voltage of $50 \mu \mathrm{V}$ and wide range of power supply $\pm 2.3 \mathrm{~V}$ to $\pm 18 \mathrm{~V}$. Gain equation for this amplifier is given in equation (1). A gain of 100 is selected for AD620 to get $4.1 \mathrm{mV}$ for every $1{ }^{\circ} \mathrm{C}$ change in the stack temperature. The value of $R_{\mathrm{G}}$ is selected as $499 \Omega$ for the required gain of 100 .

$$
\text { Gain }=\left\{\left[49.4 \mathrm{k} \Omega / \mathrm{R}_{\mathrm{G}}\right]+1\right\}
$$




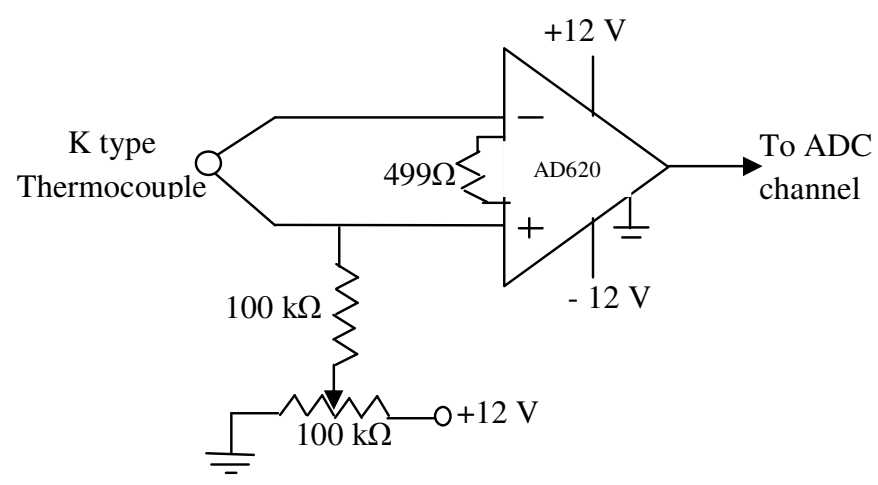

Figure 3. Data acquisition from the sensor

\subsection{Analog to Digital Converter}

The output of AD620 is connected to the on-chip serial ADC of 10-bit resolution and the analog voltage is converted to 10-bit digital code. ADC has the resolution of $3.23 \mathrm{mV}$ at $\mathrm{V}_{\text {ref }}=3.3 \mathrm{~V}$ and conversion time of $2.44 \mu \mathrm{sec}$.

\subsection{ARM7 Microcontroller}

LPC 2129 is an ARM7TDMI manufactured by Philips Semiconductor. It is a 64 pin package with 256 kilobytes of high speed flash memory, 32 bit RISC machine with $16 \mathrm{kB}$ on-chip RAM; four channel 10-bit ADC, 32 bit timers along with PWM and RTC, 46 general purpose I/Os, $\mathrm{I}^{2} \mathrm{C}$ interface facility. Because of all these features this microcontroller is best suited for single chip instrument design [13].

\subsection{LCD}

A $16 \times 2$ line LCD is used to display the temperature of the stack [14]. LCD requires low power, provides backlight during low light vision. LCD is interfaced with the microcontroller in nibble mode (only 4 bits of command/ data are transmitted at a time). The data lines D3 to D7 of LCD are connected to P0.4 to P0.7 and control lines RS (Register Select), R/W (Read/Write) and E (Enable) are connected to P0.2, P0.3 and P0.10 port pins of LPC2129 respectively [13].

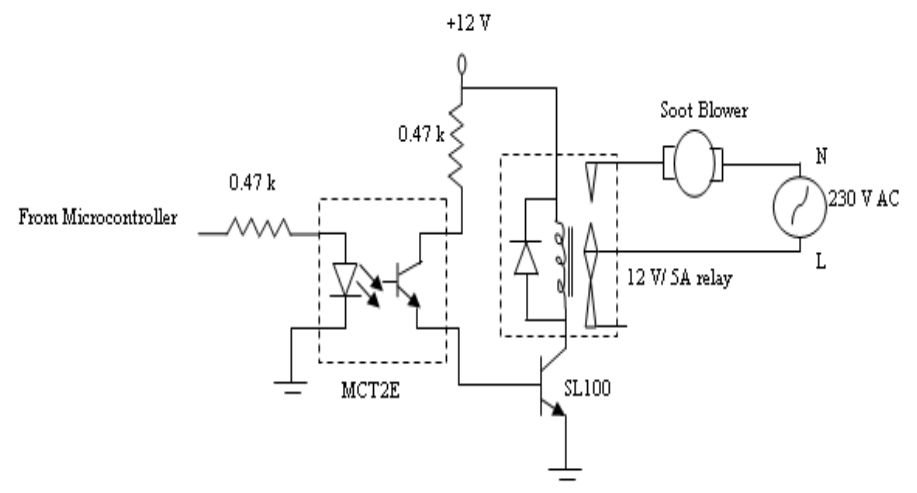

Figure 4. Soot blower control circuit

The output signal from the microcontroller is connected to opto-coupler MTC2E to electrically separate the microcontroller circuit with the soot blower motor. The soot blower motor is driven 
by $12 \mathrm{~V} / 5$ A relay and SL100 transistor [15]. When the error in temperature of stack exceeds $20^{\circ} \mathrm{C}$, the microcontroller sends a high signal on one of its port pins P0.1, which turns on the transistor SL100, through the opto-coupler. Then soot blower motor receives $230 \mathrm{~V}$ and the motor runs. This motor helps to remove soot formation in the boiler by blowing steam with pressure. The soot blower motor automatically stops, when the error in stack temperature is less than $5{ }^{\circ} \mathrm{C}$. The next measurement of stack temperature is made after one hour as the temperature is a slow varying parameter and the cycle is repeated once again.

\section{THE SOFTWARE}

The flow chart of the complete experiment is shown in Figure 5. Embedded C under KEIL's Integrated Development Environment (IDE) with $\mu$ Vision 4.0 is used for implementation of software. Two separate sub-routines are implemented, one for acquiring the sensor signal and another for displaying the stack temperature. The main program finds the error in stack temperature by finding the difference between set point and the measured value of stack temperature. If the error is greater than or equal to $20^{\circ} \mathrm{C}$, then the soot blower motor is turned on until it becomes less than $5{ }^{\circ} \mathrm{C}$. These steps are repeated after a time delay of one hour, as the deposition of soot in one hour cannot cause the stack temperature to rise much.

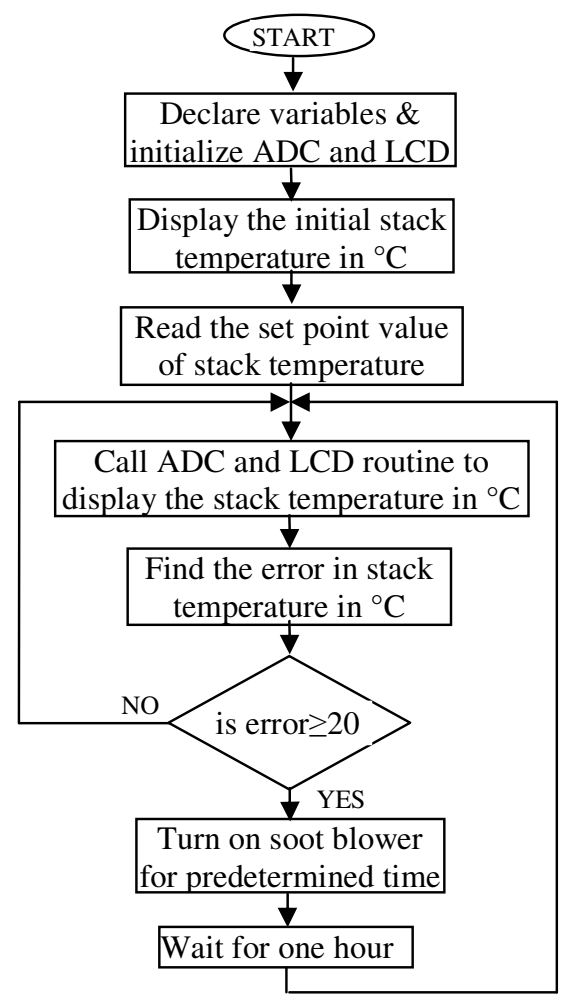

Figure 5. Flowchart of soot blower control system

\section{EXPERIMENTS AND RESULTS}

A cuboid shaped furnace of $2.5 \mathrm{~kW}$ power, insulated by glass wool wall and a blower motor set up is used for experimental purpose. The furnace has dimensions of $49 \mathrm{~cm}$ length $\times 40 \mathrm{~cm}$ height $\times 40 \mathrm{~cm}$ breadth, with resistive heating. The temperature range of this furnace is $30^{\circ} \mathrm{C}$ to $1200^{\circ} \mathrm{C}$. This furnace is considered as a stack for conducting experiments, where the temperature is read by a $\mathrm{K}$ type thermocouple. The blower motor with a water lift capacity of $520 \mathrm{~mm}$ and an air 
blowing capacity of $370 \mathrm{~km} / \mathrm{hr}$ at $1200 \mathrm{RPM}$ is used as a soot blower. The photograph of the entire experimental set up is shown in Figure 6.

Experiments are conducted in laboratory by entering the set point value of the stack temperature initially. The temperature of the furnace is increased slowly. The output analog signal from the temperature sensor, the Instrumentation amplifier and the corresponding digital code by the 10-bit in-built ADC are tabulated in Table 1. This table shows that the resolution of 10-bit in-built ADC is sufficient for the measurement of stack temperature using thermocouple and AD620. The ADC can read the stack temperature up to $800{ }^{\circ} \mathrm{C}$. The voltage that would be obtained from AD620 for $800{ }^{\circ} \mathrm{C}$ is $3.28 \mathrm{~V}$. The Figure 7 and Figure 8 shows the display on LCD when the error in temperature is less than $20^{\circ} \mathrm{C}$ and more than or equal to $20{ }^{\circ} \mathrm{C}$ respectively.

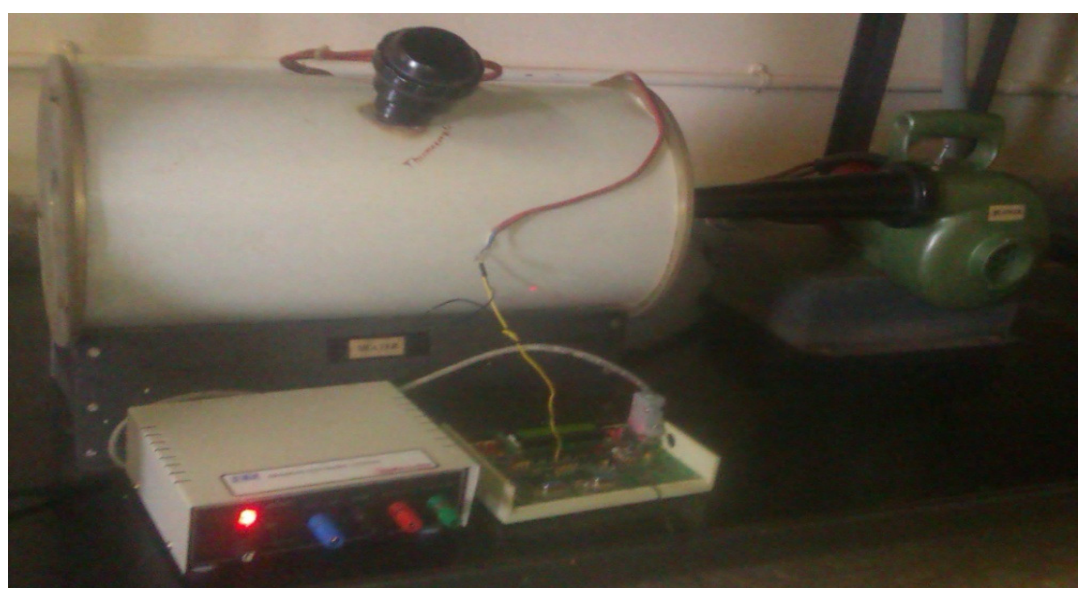

Figure 6. Experimental set up

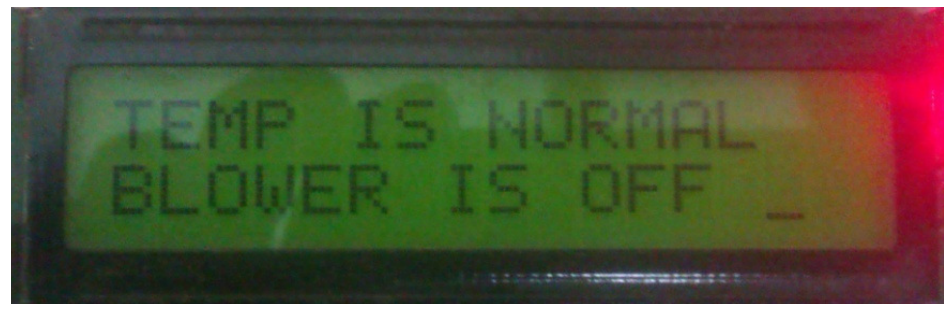

Figure 7. Display when error in temperature is less than $20^{\circ} \mathrm{C}$

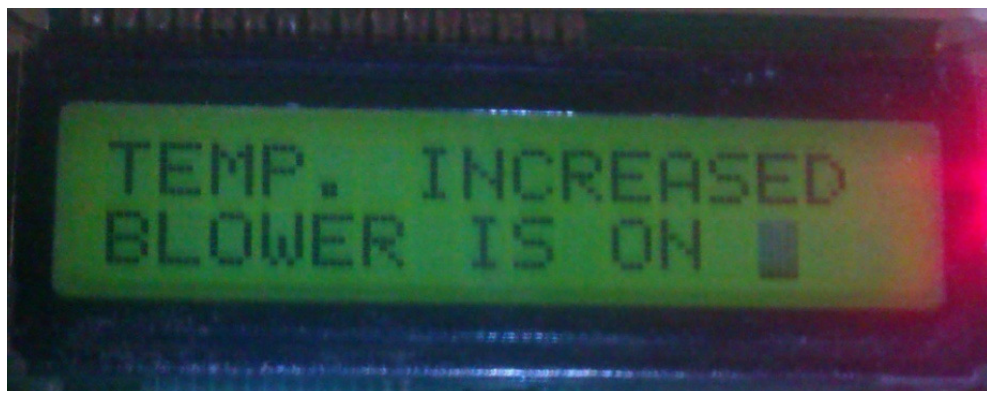

Figure 8. Display when error in temperature is greater than $20^{\circ} \mathrm{C}$ 
The digital code obtained from the in-built ADC is compared with the set point value of the stack temperature in the microcontroller. If the difference is more than $20^{\circ} \mathrm{C}$, then the soot blower motor is turned on until the difference in temperature becomes less than $5{ }^{\circ} \mathrm{C}$. The time delay is obtained by programming the in-built timer of ARM7TDMI, LPC2129. If the difference of temperature is less than $20{ }^{\circ} \mathrm{C}$ then no action is initiated. This way the stack temperature is monitored and the duration for which the blower is on is scientifically controlled continuously.

Table 1. Signals at various points

\begin{tabular}{|c|c|c|c|}
\hline $\begin{array}{c}\text { Stack } \\
\text { Temp. } \\
\text { in }\end{array}$ & $\begin{array}{c}\text { O/P voltage } \\
\text { from sensor } \\
\text { in } \mathbf{~ m V}\end{array}$ & $\begin{array}{c}\text { O/P voltage } \\
\text { from AD620 } \\
\text { in V }\end{array}$ & $\begin{array}{c}\text { Digital code } \\
\text { from ADC in } \\
\text { decimal }\end{array}$ \\
\hline 100 & 4.10 & 0.410 & 127 \\
\hline 120 & 4.92 & 0.492 & 153 \\
\hline 140 & 5.74 & 0.574 & 178 \\
\hline 160 & 6.56 & 0.656 & 203 \\
\hline 180 & 7.38 & 0.738 & 229 \\
\hline 200 & 8.20 & 0.820 & 254 \\
\hline 220 & 9.02 & 0.902 & 280 \\
\hline 240 & 9.84 & 0.984 & 305 \\
\hline 260 & 10.66 & 1.066 & 331 \\
\hline 280 & 11.48 & 1.148 & 356 \\
\hline 300 & 12.30 & 1.230 & 381 \\
\hline
\end{tabular}

\section{CONCLUSION}

In this paper, design and implementation of real time automatic soot blower control system is presented. The soot blower control system is designed and implemented using LPC2129, ARM7TDMI microcontroller and tested by carrying out the experiments. The performance of the system is compared with the designed theoretical values and an error of \pm 1 is observed. This real time embedded based automated system whose operation depends upon stack temperature can be used for controlling the soot blower motor, instead of conventional method. This will definitely improve the boiler efficiency. Because of the use of ARM7 microcontroller, the system is more reliable, compact and economical. In this way the system can be viewed as low cost design for process industry.

\section{REFERENCES}

[1] K. Gouri Shankar, (2008) "Control of Boiler Operation using PLC-SCADA,” International Multi Conference of Engineers and Computer Scientists, Vol. 2, ISBN: 978-988-17012-1-3.

[2] Sunit Shah, D.M. Adhyaru, (2011) "Boiler Efficiency Analysis using Direct Method," IEEE International Conference on Current Trends in Technology, ISBN: 978-1-4577-2168-7/11.

[3] Chayalakshmi C.L, D.S. Jangamshetti, Savita Sonoli, (2013) "Design and Development of an ARM platform based Embedded System for Measurement of Boiler Efficiency," IEEE Symposium on Industrial Electronics and Applications, Malaysia, ISBN: 978-1-4799-1124-0.

[4] Mehmet Kanogula, Ibrahim Dincerrb, Marc A Rosen, (2007) "Understanding Energy and Exergy Efficiencies for improved Energy Management in Power Plants,” Energy Policy, Vol. 35, pp. 39673978.

[5] Carl Jochen Winter, (2007) "Energy Efficiency, no: It's Exergy Efficiency,” International Journal of Hydrogen Energy, Vol. 32, pp. 4109-4111.

[6] Amit Kumar Jain, (2012) “An Approach towards Efficient Operation of Boilers," International Journal of Scientific and Engineering Research, Vol. 3(6). 
[7] N. Hare, M. G. Rasul, S. Moazzem, "A Review on Boiler Deposition/Foulage Prevention and Removal Techniques for Power Plant," Recent Advances in Energy \& Environment, ISSN: 17905095, ISBN: 978-960-474-159-5.

[8] Coreantrell, Stephen Idem, (2010) "On-line Performance Model of the Convection passes of a Pulverized Coal Boiler,” Heat Transfer Engineering, Vol. 31(14), 1173-1183.

[9] Rahul Dev Gupta, Sudhir Gai, Ajai Jain, (2011) "Energy Efficiency Improvement Strategies for Industrial Boilers: Case Study,” Journal of Engineering and Technology, Vol. 1 (1).

[10] Mohi Eldin, Ibrahim Mohammed Elfatih Mohammed, (2012) "Design of Boilers Soot blower Control System for Power Station Using Programmable Logic Controller," Sudan University of Science and Technology.

[11] Bhavesh Jinjala, Rashmikant. N. Shukla, (2013) "Energy Conservation in Boiler by Variable Speed Drives (VSD)," International Journal of Innovative Research in Science, Engineering and Technology, ISSN: 2319-8753, Vol. 2(4).

[12] R Saidurn, J U Ahamad, H H Masjuki, (2010) "Energy, Exergy and Economical Analysis of Industrial Boilers,” Energy Policy, Vol. 38, pp. 2188-2197.

[13] Philips LPC2129 user manual, 2004 at http//: www.semiconductors.philips.com

[14] Oriole LCD Module User Guide.

[15] L. Shrimanth Sudheer, Immanuel J., P. Bhaskar, and Parvathi C. S., (2013) "ARM7 Microcontroller based Fuzzy Logic Controller for Liquid Level Control System,” International Journal of Electronics and Communication Engineering and Technology, Vol. 4(2), pp. 217-224.

\section{Authors:}

Chayalakshmi C.L. completed B.E.in Instrumentation Engineering in the year of 1996 from B.V.B. College of Engineering and Technology, Hubli and did M. Tech in Digital Communication in the year 2006 from Basaveshwar Engineering College, Bagalkot. She has teaching experience of 18 years. She is pursuing research in the area of embedded system for industrial automation. Her area of interest covers Embedded Systems, Industrial Instrumentation, Signal conditioning. Presently she is working as an Associate Professor in Instrumentation Technology, Basveshwar Engineering College, Bagalkot, Karnataka, India.

Dr. Dakshayani S. Jangamshetti obtained B.E. in Electrical Engineering from Karnataka University Dharwad in the year 1985, M.Tech. in Instrumentation from IIT Kharagpur and Ph. D. in Speech signal Processing from IIT Bombay in the year 2003. She has 29 years of teaching and 11 years of R \& D experience. Her area of research and interest is in signal processing. She has guided two PhD scholars and two scholars are currently doing research. She has more than 30 technical publications in International/ national journals/conference. Till date she has organized

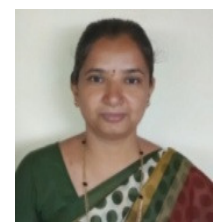
15 AICTE/ISTE/BEC-TEQIP sponsored seminars/workshops and training programs. She has visited Orlando (USA) to present research findings in a conference. She is a senior member of IEEE, FIE, LMISTE, IETE, and BME. She is awarded with "Outstanding Branch Counselor" for the year 2014.

Dr. Savita Sonoli completed B.E (E\&CE), from BVBCET, Hubli, M.Tech (Industrial Electronics.) from NITK, Surathkal, and Ph.D (Embedded System) from SK University, Ananthpur. She has worked as Professor and Head, E \& CE department at PDIT, Hospet and Sir MVIT, Bangalore. Presently working as a Professor \& Head, E \& CE dept. M. Tech (DCN) Co-ordinator and E \& CE research centre head at RYMEC, Bellary. Having 16 years of academic experience she has worked at various capacities as Academic Dean, IIIC co-ordinator, University Guest faculty member, Resource Person, Reviewer, and Technical Sessions Chair Person. Many of her projects have been sponsored by KSCST

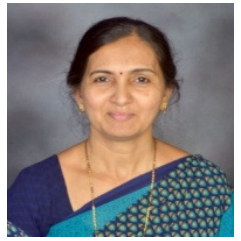
and received cash prize. She has also got best project and paper award. She has more than 10 research paper publications in National and International journals and conference to her credit. Presently 3 research scholars are pursuing $\mathrm{Ph}$. D under her in VTU. She has visited Michigan \& Wisconsin states of USA as GSE team member in 2010. She is a member for professional bodies like MISTE, AMIE, ISCA, ISOI, IEEE and IAENG. 